\title{
FLT3 in lineage specification and plasticity
}

\author{
Sarah Greenblatt ${ }^{1}$ and Donald Small ${ }^{1,2}$ \\ ${ }^{1}$ Department of Oncology, Johns Hopkins University School of Medicine, Baltimore, MD \\ 2 Department of Pediatrics, Johns Hopkins University School of Medicine, Baltimore, MD \\ Correspondence to: Donald Small, email: donsmall@jhmi.edu \\ Keywords: FLT3, B220, leukemia, lineage, differentiation \\ Received: May 14, 2012, Accepted: May 26, 2012, $\quad$ Published: May 27, 2012 \\ Copyright: () Greenblatt et al. This is an open-access article distributed under the terms of the Creative Commons Attribution License, which \\ permits unrestricted use, distribution, and reproduction in any medium, provided the original author and source are credited.
}

\section{ABSTRACT:}

FLT3 is a receptor tyrosine kinase that is expressed in CD34+ hematopoietic stem/ progenitor cells (HSPCs) and is important for both normal myeloid and lymphoid differentiation. FLT3 expression in Pax 5 negative lymphoid precursors coincides with a window of multilineage differentiation potential in mice and humans. Recent work has shown that FLT3 activating mutations can collaborate with a Nup98-HoxD13 mutation to induce an aggressive acute leukemia. The leukemic initiating population in this model displayed properties of both lymphoid and myeloid precursors, making it a useful tool to study the role of FLT3 in lineage plasticity. Through a variety of assays, the leukemic initiating population was shown to be restricted to myeloid differentiation, suggesting that the B-lineage properties in these cells are due to the priming of lymphoid transcription programs in multipotent progenitors rather than a true capacity for B-cell maturation. The development of an undifferentiated myeloid leukemia in this model, also has implications for the role of FLT3 in the inhibition of myeloid differentiation. Here we discuss the insights gained from this model.

\section{INTRODUCTION}

The commitment of cells to myeloid or lymphoid lineage development is considered to be an irreversible process, whereby distinct gene expression programs are triggered involving epigenetic changes in DNA and protein modification. However, there is evidence that multipotent progenitor cells prime several different lineage programs at low levels in order to respond rapidly to external stimuli [1]. Differentiation requires both an increase in lineage specific genes and a decrease in gene expression associated with alternative lineages. Therefore, dysregulation of gene expression by oncogenic mutations can lead to lineage conversion or multilineage properties in these primitive cells.

Activating mutations of the FLT3 receptor are some of the most common alterations in acute myeloid leukemia (AML) and have been extensively studied in patient samples, cell lines, and model systems [2-5]. We recently published a study describing a mouse model of cooperation between a knock-in of a FLT3 internal tandem duplication (ITD) mutation and a transgenic Nup98HoxD13 (NHD13) translocation [6]. While the FLT3/
ITD mutation alone induces a lethal myeloproliferative neoplasm (MPN) [7] and the Nup98-HoxD13 translocation alone produces a myelodysplastic syndrome (MDS), mice bred to express both mutations develop an acute leukemia with short latency and $100 \%$ penetrance.

Initially, the leukemia observed in this model appeared to express cell surface markers characteristic of both primitive myeloid and lymphoid development. The induction of a biphenotypic leukemia in this model would be surprising given the clinical data documenting the role of both Nup98 translocations and FLT3/ITD mutations in myeloid disease. The case reports describing patients harboring a Nup98-HoxD13 translocation have all reported myeloid malignancies; 1 case of therapy related acute erythroid leukemia and 3 cases with acute myelomonocytic leukemia [8-11]. To date, no Nup98 translocations have been observed in a patient with a B-cell malignancy [12]. Similarly, FLT3-ITD mutations are largely restricted to subtypes of AML, and are rarely reported in cases of acute lymphoblastic leukemia (ALL) [2, 13-14]. Finally, the FLT3/ITD-NHD13 model mimics the stepwise progression of a pre-leukemic disorder characterized by myelodyspasia, to overt leukemia that is frequently observed in patients. Approximately, $30 \%$ of 
MDS cases progress to AML, while the progression of MDS to ALL is rare [15].

\section{FLT3 in normal and malignant B-cells}

Although FLT3 activating mutations appear to be primarily restricted to myeloid leukemias in patients, wildtype FLT3 is known to be expressed in lymphoid precursors and is expressed at low levels in nearly $100 \%$ of B-cell ALLs, suggesting a role for the receptor in early B-cell development [16-18]. Furthermore, subsets of ALL associated with specific chromosomal translocations such as MLL rearrangements have been shown to express FLT3 at high levels [19]. Although FLT3 activating mutations occur rarely in lymphoid leukemia, they occur at a higher frequency in subtypes of childhood leukemia such as hyperdiploid and MLL rearranged ALL [20-21].

In contrast to what is observed in patients, many mouse models that result in expression of FLT3 activating mutations through retroviral transduction of bone marrow or the generation of transgenic or "knock-in" mice have reported leukemias that express cell surface markers characteristic of biphenotypic or lymphoid development. For example, transduction of bone marrow with a FLT3 tyrosine kinase domain mutation results in a high proportion of lymphoid disease [22]. The combination of FLT3/ITD mutations with oncogenic fusions such as MLL-SEPT6 and AML1-ETO has also yielded a subset of mice with lymphoid disease [23-24]. In addition, a retroviral insertional mutagenesis screen in the FLT3/ ITD knock-in background identified a high proportion of lymphoid leukemias [25].

\section{Regulation of FLT3 in murine B-cell development}

One explanation for the development of a myeloid disease with early B-lymphoid properties in mice is that regulation of FLT3 expression is critical for early B-cell maturation. Gene knock-out studies have illustrated the importance of the balance between FLT3 and Pax5, a transcription factor that is critical for B-lineage commitment [26-27]. Pax 5-/ pre-B cells are susceptible to myeloid lineage switching when transduced with $\mathrm{C} /$ EBP $\alpha$ or the GATA family of transcription factors, but lose this ability after Pax5 induction [28]. This window of multilineage developmental potential is associated with FLT3 expression [29]. Holmes et al. have shown that Pax 5 deficient proB cells express high levels of FLT3, but that it is repressed upon ectopic Pax5 expression. Further studies in mice have shown that knock-down or over expression of FLT3 can have a profound impact on B-cell development. FLT3 $3^{--}$mice have reduced numbers of B-cell precursors in the bone marrow, though normal numbers of functional B cells are present in the periphery and mice lacking FLT3 ligand have decreased numbers of myeloid and B-lymphoid progenitors [30-32]. Conversely, forced over expression of FLT3 or FLT3 ligand in mouse bone marrow results in decreased numbers of $\mathrm{B} 220^{+} \mathrm{CD} 19^{+}$cells $[29,33]$. In a more physiologically relevant system, where the FLT3/ITD mutation is expressed under the endogenous promoter, mice develop a block in differentiation at an early pro B-cell stage [34]. Taken together, these studies indicate that temporal control of FLT3 expression is critical for B-cell maturation.

Several murine models of hematopoietic malignancy have reported leukemias that co-express cell surface markers consistent with both myeloid and lymphoid cells, typically using B220 as evidence of B-cell differentiation. However, B220 appears early in hematopoietic differentiation and can also be expressed on many different cell types. Through sorting and transplantation of progenitor cell populations from a leukemic FLT3/ITD-NHD13 donor mouse, we showed that the ability to transplant the disease was restricted to a $\mathrm{B} 220^{+}$population with the immunophenotype of a multipotent progenitor. However, despite expression of B220, the leukemic initiating population was restricted to myeloid differentiation in vitro. This population had no other B-lymphoid properties. The cells did not display B-cell specific transcription factor expression or any other cell surface markers consistent with B-cell precursors. Although this population had D-to-J rearrangements of the IgH locus, they did not show any signs of V-to-DJ rearrangements, which are definitive for B- lymphoid cells. Single cell analysis of CD19- B-precursor populations in the mouse bone marrow have shown that recombination activating genes can be detected at low levels in most multipotent progenitor cells, a population that retains the capacity for myeloid differentiation. Thus, the presence of D-to-J rearrangements and surface B220 expression may be due to the priming of lymphoid differentiation programs at low levels in multipotent progenitors, rather than evidence for lymphoid differentiation.

\section{FLT3 and B220 expression}

There is previous evidence of a connection between FLT3 signaling and the expansion of hematopoietic stem and progenitor cells (HSPCs) expressing B220. One study identified a population of CD19-B220 ${ }^{+}$c-KIT ${ }^{+} \mathrm{FLT}^{+}$cells as early B-lymphoid precursors in juvenile mouse bone marrow that is highly dependent on FLT3 expression for survival [35-36]. These cells possess the potential to produce both lymphoid and myeloid colonies in vitro. Other studies observed that FLT3 ligand induces the outgrowth of $\mathrm{Mac}-1^{+} / \mathrm{B} 220^{+}$mouse bone marrow progenitor cells restricted to macrophage differentiation that co-express early B-cell associated genes [37]. PreB-cell progenitors with myeloid characteristics have also been described when murine cells are transformed with several oncogenic receptor tyrosine kinases [38]. Together, 
these studies suggest that a population of pre-B cells with bilineage potential exists within juvenile mice that is dependent on FLT3 expression and highly susceptible to transformation.

Recent work has shown that a leukemia initiating population with lymphoid characteristics can exist in patients with AML, suggesting that the presense of a myeloid restricted $\mathrm{B} 220$ expressing cell is not a mouse specific phenomenon [39]. In this study, CALM/AF10 positive AML samples were shown to co-express B220 and CD34, a marker used to define HSPC populations, and had detectable clonal immunoglobulin rearrangements. Rearrangements of the IgH locus have been observed in a significant number of AML cases, suggesting that a larger subset of leukemias may also be derived from a progenitor population with lymphoid characteristics [40].

\section{FLT3 in lineage specification}

The presence of a FLT3 activating mutation can also affect the lineage restriction of HSPCs. Although FLT3 mutations are typically categorized by their ability to promote survival and proliferation, accumulating data has suggested that FLT3/ITD activating mutations can also contribute to a block in differentiation [41-42]. Radomska et al. has shown that constitutive activation of FLT3 can inhibit $\mathrm{CEBP} \alpha$ function through ERK1/2 mediated phosphorylation, resulting in a block in differentiation in both cell lines and patient samples. Treatment of primary blasts with the FLT3 inhibitor CEP701 was able to partially reverse this differentiation block, as evidenced by increased expression of CEPB $\alpha$ and Pu.1 and enhanced granulocytic differentiation. This work suggests that signaling downstream of the constitutively activated receptor may alter the activity of transcription factors that are critical for myeloid differentiation.

The distribution of disease in the FLT3/ITD-NHD13 model also supports the role of FLT3 mutations in the impairment of differentiation. Although the NHD13 alone mice all develop a myelodysplastic syndrome, a subset of these mice are known to progress to differentiated leukemias of both the myeloid and lymphoid lineages [43]. These mice develop a variety of differentiated myeloid neoplasms including acute megakaryocytic, erythroid, and myelomonocytic leukemias. However, when this mutation is combined with the FLT3/ITD knock-in mutation, mice develop strictly minimally differentiated myeloid leukemias. This difference in leukemia subtype, suggests that the presence of a FLT3/ITD mutation in this system results in the transformation of very early myeloid precursors that are impaired in maturation. Accordingly, HSPCs isolated from the FLT3/ITD-NHD13 mice showed an impaired ability of to differentiate in vitro [Greenblatt and Small, unpublished data], even compared to the NHD13 or FLT3/ITD alone mice [44].

In the FLT3/ITD-NHD13 mice, an early genetic event leading to loss of the wildtype FLT3 allele allows us to track cells originating from the leukemic initiating population. Loss of heterozygosity is never found in megakaryocytic/erythroid progenitors or CD19+ B-cells populations, indicating that the leukemic initiating population does not contribute to these lineages. These data provide further evidence that FLT3/ITD mutations play a role in the regulation of differentiation and lineage restriction of the leukemic stem cell. The contribution of both mutations to impairment in differentiation may also explain why the concomitant expression of a Nup98 translocation and FLT3/ITD mutation results in a short latency to disease in mice and a poor prognosis in patients.

\section{CONCLUSION}

This cumulative work suggests that regulation of FLT3 expression is critical for both myeloid and lymphoid differentiation. Disturbance of FLT3 through overexpression or constitutive activation by FLT3 activating mutations can result in leukemias with promiscuous lineage properties. While these properties may make the cells more difficult to treat, they may also provide a unique target for treatment since the leukemic initiating population may express a cell surface profile distinct from normal stem cells.

\section{REFERENCE}

1. $\mathrm{Hu} \mathrm{M}$, Krause D, Greaves $\mathrm{M}$, Sharkis $\mathrm{S}$, Dexter M, Heyworth C, Enver T. Multilineage gene expression precedes commitment in the hemopoietic system. Genes Dev. 1997; 11(6):774-785.

2. Nakao M, Yokota S, Iwai T, Kaneko H, Horiike S, Kashima K, Sonoda Y, Fujimoto T, Misawa S. Internal tandem duplication of the flt 3 gene found in acute myeloid leukemia. Leukemia. 1996; 10(12):1911-1918.

3. Gilliland DG and Griffin JD. The roles of FLT3 in hematopoiesis and leukemia. Blood. 2002; 100(5):15321542.

4. Stirewalt DL and Radich JP. The role of FLT3 in haematopoietic malignancies. Nat Rev Cancer. 2003; 3(9):650-665.

5. Levis M and Small D. FLT3: ITDoes matter in leukemia. Leukemia. 2003; 17(9):1738-1752.

6. Greenblatt S, Li L, Slape C, Nguyen B, Novak R, Duffield A, Huso D, Desiderio S, Borowitz MJ, Aplan P, Small D. Knock-in of a FLT3/ITD mutation cooperates with a NUP98-HOXD13 fusion to generate acute myeloid leukemia in a mouse model. Blood. 2012; 119(12):2883-94.

7. Li L, Piloto O, Nguyen HB, Greenberg K, Takamiya K, Racke F, Huso D, Small D. Knock-in of an internal tandem duplication mutation into murine FLT3 confers myeloproliferative disease in a mouse model. Blood. 2008; 111(7):3849-3858. 
8. Raza-Egilmez SZ, Jani-Sait SN, Grossi M, Higgins MJ, Shows TB, Aplan PD. NUP98-HOXD13 gene fusion in therapy-related acute myelogenous leukemia. Cancer Res. 1998; 58(19):4269-4273.

9. Arai Y, Kyo T, Miwa H, Arai K, Kamada N, Kita K, Ohki M. Heterogenous fusion transcripts involving the NUP98 gene and HOXD13 gene activation in a case of acute myeloid leukemia with the $\mathrm{t}(2 ; 11)(\mathrm{q} 31 ; \mathrm{p} 15)$ translocation. Leukemia. 2000; 14(9):1621-1629.

10. Hidaka E, Tanaka M, Matsuda K, Ishikawa-Matsumura M, Yamauchi K, Sano K, Honda T, Wakui K, Yanagisawa R, Nakazawa Y, Sakashita K, Shiohara M, Ishii E, Koike K. A complex karyotype, including a three-way translocation generating a NUP98-HOXD13 transcript, in an infant with acute myeloid leukemia. Cancer Genet Cytogenet. 2007; 176(2):137-143.

11. Emerenciano M, Meyer C, Macedo-Silva ML, de Meis E, Dobbin JA, Marschalek R, Pombo-de-Oliveira MS. Backtracking to birth of the NUP98-HOXD13 gene fusion in an infant acute myeloid leukemia. Leukemia. 2011; 25(7):1192-1194.

12. Gough SM, Slape C, Aplan PD. NUP98 gene fusions and hematopoietic malignancies: common themes and new biologic insights. Blood. 2011; 118(24):6247-6257.

13. Yamamoto Y, Kiyoi H, Nakano Y, Suzuki R, Kodera Y, Miyawaki S, Asou N, Kuriyama K, Yagasaki F, Shimazaki C, Akiyama H, Saito K, Nishimura M, Motoji T, Shinagawa K, Takeshita A, Saito H, Ueda R, Ohno R, Naoe T. Activating mutation of D835 within the activation loop of FLT3 in human hematologic malignancies. Blood. 2001; 97(8):2434-2439.

14. Thiede C, Steudel C, Mohr B, Schaich M, Schakel U, Platzbecker U, Wermke M, Bornhauser M, Ritter M, Neubauer A, Ehninger G, Illmer T. Analysis of FLT3-activating mutations in 979 patients with acute myelogenous leukemia: association with FAB subtypes and identification of subgroups with poor prognosis. Blood. 2002; 99(12):4326-4335.

15. Disperati P, Minden MD, Gupta V, Schimmer AD, Schuh AC, Yee KW, Kamel-Reid S, Chang H, Xu W, Brandwein JM. Acute promyelocytic leukemia in patients aged 70 years and over -- a single center experience of unselected patients. Leuk Lymphoma. 2007; 48(8):1654-1658.

16. Birg F, Courcoul M, Rosnet O, Bardin F, Pebusque MJ, Marchetto S, Tabilio A, Mannoni P, Birnbaum D. Expression of the FMS/KIT-like gene FLT3 in human acute leukemias of the myeloid and lymphoid lineages. Blood. 1992; 80(10):2584-2593.

17. Carow CE, Levenstein M, Kaufmann SH, Chen J, Amin S, Rockwell P, Witte L, Borowitz MJ, Civin CI, Small D. Expression of the hematopoietic growth factor receptor FLT3 (STK-1/Flk2) in human leukemias. Blood. 1996; 87(3):1089-1096.

18. Rosnet O, Buhring HJ, Marchetto S, Rappold I, Lavagna C, Sainty D, Arnoulet C, Chabannon C, Kanz L, Hannum
C, Birnbaum D. Human FLT3/FLK2 receptor tyrosine kinase is expressed at the surface of normal and malignant hematopoietic cells. Leukemia. 1996; 10(2):238-248.

19. Armstrong SA, Staunton JE, Silverman LB, Pieters R, den Boer ML, Minden MD, Sallan SE, Lander ES, Golub TR, Korsmeyer SJ. MLL translocations specify a distinct gene expression profile that distinguishes a unique leukemia. Nat Genet. 2002; 30(1):41-47.

20. Armstrong SA, Mabon ME, Silverman LB, Li A, Gribben JG, Fox EA, Sallan SE, Korsmeyer SJ. FLT3 mutations in childhood acute lymphoblastic leukemia. Blood. 2004; 103(9):3544-3546.

21. Taketani T, Taki T, Sugita K, Furuichi Y, Ishii E, Hanada R, Tsuchida M, Sugita K, Ida K, Hayashi Y. FLT3 mutations in the activation loop of tyrosine kinase domain are frequently found in infant ALL with MLL rearrangements and pediatric ALL with hyperdiploidy. Blood. 2004; 103(3):1085-1088.

22. Grundler R, Miething C, Thiede C, Peschel C, Duyster J. FLT3-ITD and tyrosine kinase domain mutants induce 2 distinct phenotypes in a murine bone marrow transplantation model. Blood. 2005; 105(12):4792-4799.

23. Ono R, Nakajima H, Ozaki K, Kumagai H, Kawashima T, Taki T, Kitamura T, Hayashi Y, Nosaka T. Dimerization of MLL fusion proteins and FLT3 activation synergize to induce multiple-lineage leukemogenesis. J Clin Invest. 2005; 115(4):919-929.

24. Schessl C, Rawat VP, Cusan M, Deshpande A, Kohl TM, Rosten PM, Spiekermann K, Humphries RK, Schnittger S, Kern W, Hiddemann W, Quintanilla-Martinez L, Bohlander SK, Feuring-Buske M, Buske C. The AML1-ETO fusion gene and the FLT3 length mutation collaborate in inducing acute leukemia in mice. J Clin Invest. 2005; 115(8):21592168.

25. Greenberg K, Li L, Huso D, Wolff L, Small D. Retroviral Insertional Mutagenesis Reveals Genes That Cooperate with FLT3-ITD in Leukemogenesis. ASH Annual Meeting Abstracts. 2009; 114: 1960

26. Nutt SL, Heavey B, Rolink AG, Busslinger M. Commitment to the B-lymphoid lineage depends on the transcription factor Pax5. Nature. 1999; 401(6753):556-562.

27. Cobaleda C, Schebesta A, Delogu A, Busslinger M. Pax5: the guardian of B cell identity and function. Nat Immunol. 2007; 8(5):463-470.

28. Heavey B, Charalambous C, Cobaleda C, Busslinger M. Myeloid lineage switch of Pax 5 mutant but not wild-type $\mathrm{B}$ cell progenitors by C/EBPalpha and GATA factors. Embo J. 2003; 22(15):3887-3897.

29. Holmes ML, Carotta S, Corcoran LM, Nutt SL. Repression of Flt3 by Pax 5 is crucial for B-cell lineage commitment. Genes Dev. 2006; 20(8):933-938.11.

30. Mackarehtschian K, Hardin JD, Moore KA, Boast S, Goff SP, Lemischka IR. Targeted disruption of the flk $2 / \mathrm{flt} 3$ gene leads to deficiencies in primitive hematopoietic progenitors. 
Immunity. 1995; 3(1):147-161.

31. McKenna HJ, Stocking KL, Miller RE, Brasel K, De Smedt T, Maraskovsky E, Maliszewski CR, Lynch DH, Smith J, Pulendran B, Roux ER, Teepe M, Lyman SD, Peschon JJ. Mice lacking flt3 ligand have deficient hematopoiesis affecting hematopoietic progenitor cells, dendritic cells, and natural killer cells. Blood. 2000; 95(11):3489-3497.

32. Sitnicka E, Bryder D, Theilgaard-Monch K, Buza-Vidas $\mathrm{N}$, Adolfsson J, Jacobsen SE. Key role of flt3 ligand in regulation of the common lymphoid progenitor but not in maintenance of the hematopoietic stem cell pool. Immunity. 2002; 17(4):463-472.

33. Karsunky H, Merad M, Cozzio A, Weissman IL, Manz MG. Flt3 ligand regulates dendritic cell development from Flt3+ lymphoid and myeloid-committed progenitors to Flt3+ dendritic cells in vivo. J Exp Med. 2003; 198(2):305-313.

34. Li L, Zhang L, Fan J, Greenberg K, Desiderio S, Rassool FV, Small D. Defective nonhomologous end joining blocks B-cell development in FLT3/ITD mice. Blood. 2011; 117(11):3131-3139.

35. Ogawa $\mathrm{M}$, ten Boekel E, Melchers F. Identification of CD19(-)B220(+)c-Kit(+)Flt3/Flk-2(+)cells as early B lymphoid precursors before pre-B-I cells in juvenile mouse bone marrow. Int Immunol. 2000; 12(3):313-324.

36. Balciunaite G, Ceredig R, Massa S, Rolink AG. A B220+ CD117+ CD19- hematopoietic progenitor with potent lymphoid and myeloid developmental potential. Eur J Immunol. 2005; 35(7):2019-2030.

37. Dannaeus K, Johannisson A, Nilsson K, Jonsson JI. Flt3 ligand induces the outgrowth of Mac-1+B220+ mouse bone marrow progenitor cells restricted to macrophage differentiation that coexpress early B cell-associated genes. Exp Hematol. 1999; 27(11):1646-1654.

38. Holmes KL, Pierce JH, Davidson WF, Morse HC, 3rd. Murine hematopoietic cells with pre-B or pre-B/myeloid characteristics are generated by in vitro transformation with retroviruses containing fes, ras, abl, and src oncogenes. J Exp Med. 1986; 164(2):443-457.

39. Deshpande AJ, Cusan M, Rawat VP, Reuter H, Krause A, Pott C, Quintanilla-Martinez L, Kakadia P, Kuchenbauer F, Ahmed F, Delabesse E, Hahn M, Lichter P, Kneba M, Hiddemann W, Macintyre E, Mecucci C, Ludwig WD, Humphries RK, Bohlander SK, Feuring-Buske M, Buske C.Acute myeloid leukemia is propagated by a leukemic stem cell with lymphoid characteristics in a mouse model of CALM/AF10-positive leukemia. Cancer Cell. 2006; 10(5):363-374.

40. Seremetis SV, Pelicci PG, Tabilio A, Ubriaco A, Grignani F, Cuttner J, Winchester RJ, Knowles DM, Dalla-Favera R. High frequency of clonal immunoglobulin or T cell receptor gene rearrangements in acute myelogenous leukemia expressing terminal deoxyribonucleotidyltransferase. J Exp Med. 1987; 165(6):1703-1712.

41. Zheng R, Friedman AD, Levis M, Li L, Weir EG, Small
D. Internal tandem duplication mutation of FLT3 blocks myeloid differentiation through suppression of C/EBPalpha expression. Blood. 2004; 103(5):1883-1890.

42. Radomska HS, Basseres DS, Zheng R, Zhang P, Dayaram T, Yamamoto Y, Sternberg DW, Lokker N, Giese NA, Bohlander SK, Schnittger S, Delmotte MH, Davis RJ, Small D, Hiddemann W, Gilliland DG, Tenen DG. Block of C/ EBP alpha function by phosphorylation in acute myeloid leukemia with FLT3 activating mutations. J Exp Med. 2006; 203(2):371-381.

43. Lin YW, Slape C, Zhang Z, Aplan PD. NUP98-HOXD13 transgenic mice develop a highly penetrant, severe myelodysplastic syndrome that progresses to acute leukemia. Blood. 2005; 106(1):287-295.

44. Slape C, Chung YJ, Soloway PD, Tessarollo L, Aplan PD. Mouse embryonic stem cells that express a NUP98HOXD13 fusion protein are impaired in their ability to differentiate and can be complemented by BCR-ABL. Leukemia. 2007; 21(6):1239-1248. 